\title{
Risk of thyroid nodules in subjects occupationally exposed to radiation: a cross sectional study
}

\author{
Alessandro Antonelli, Giovanni Silvano, Fabrizio Bianchi, Carmelo Gambuzza, \\ Luigi Tana, Giulio Salvioni, Vittoria Baldi, Lucia Gasperini, Lidio Baschieri
}

\begin{abstract}
Objectives-To examine, by ultrasonography the prevalence of thyroid nodules in a cross sectional study of male medical workers occupationally exposed to $x$ radiation at the Pisa hospital, in comparison with controls matched for age and sex.

Methods-50 male medical workers exposed to radiation were randomly matched for age ( \pm 2 years) with 100 male workers not occupationally exposed to ionising radiation who lived in a slightly iodine deficient area of Tuscany (Lunigiana) (control group 1), and with 100 male workers not exposed to radiation who lived in the same area (Pisa) (control group 2).

Results-Of the occupationally exposed subjects, thyroid nodules were detected in $19 / 50$ (38.0\%). Among controls, thyroid nodules were detected in $19 / 100$ subjects of control group 1 and in 13/100 of control group 2. Comparison of exposed and control groups, stratified into 30-39, 40-49, and 50-59 year old age subgroups, showed a higher significant relative risk for thyroid nodules in the exposed subjects.

Conclusion-The results suggest that occupational exposure to radiation may be a risk factor for thyroid nodules.
\end{abstract}

(Occup Environ Med 1995;52:500-504)

Keywords: thyroid nodules; occupational radiation

Institute of Clinical

Medicine II

A Antonelli

C Gambuzza

G Salvioni

$\checkmark$ Baldi

L Gasperini

L Baschieri

Institute of Radiology,

University of Pisa

G Silvano

Unit of Epidemiology

and Biostatistics,

Institute of Clinical

Physiology, CNR, Pisa

F Bianchi

Sanitary Physic Unit, USL-12 Pisa, Italy

L Tana

Correspondence to:

Alessandro Antonelli,

Clinica Medica 2, Via Roma

67, 56100, Pisa, Italy.

Accepted 28 March 1995

An increased prevalence of thyroid cancer and nodules in relation to short term, high dose exposure to ionising radiation has been found, mainly in infants and adolescents. ${ }^{14}$ There are only a few studies on the effects of long term, environmental or occupational low dose

The aim of this study was to evaluate the prevalence of nodular thyroid disease in medical workers occupationally exposed to $x$ radiation.

\section{Patients and methods}

The prevalence of nodular thyroid disease was evaluated cross sectionally by ultrasonography in subjects occupationally exposed to radiation who worked in the health service of Pisa, and was compared with control subjects matched for age and sex not occupationally exposed. We selected a control group of workers (group 1) from a slightly iodine deficient area of Tuscany (Lunigiana), and a second control group (group 2) from the same area as the exposed group (Pisa).

\section{OCCUPATIONALLY EXPOSED SUBJECTS}

The occupationally exposed men included in the study were registered in the list of the radioprotection service of the USL-12 (Pisa) on 1 September 1992, and employed in the units of orthopaedics, haemodynamics, interventional radiology, and radiotherapy $(\mathrm{n}=90)$. We have chosen these units because it is known that the exposure to $x$ radiation is generally heavier than in other units involved with $x$ rays. The mean (SD, range) cumulative dose was $67 \cdot 2(96 \cdot 0,3 \cdot 6-690 \cdot 0) \mathrm{mSv}$. The variability was extremely high. Furthermore, the dosimetric data were not reliable for the following reasons: $(a)$ the hospital file of data until 1975 is missing; (b) the method of measurement of exposure was not uniform until 1975; (c) from 1975 to 1980 a uniform method of measurement of exposure was used; and (d) the method of measurement of exposure was changed again in 1980.

For these reasons we have preferred to adopt an occupational criterion, and we selected those subjects who had occupational exposure of more than 10 years (we have chosen 10 years because other studies have reported that the mean latency time for the comparison of thyroid pathology from the first exposure to radiation is more than 10 years ${ }^{1-3}$; also because it seems long enough to achieve an effective cumulative dose).

Of the 90 subjects, 59 fitted these reported exposure..$^{5-8}$ criteria. They were examined in our unit from September 1992 to June 1993. Of these occupationally exposed subjects $28(47 \%)$ worked in orthopaedics (six technicians, 13 hospital attendants, nine physicians), $10(17 \%)$ in haemodynamics (five technicians, four hospital attendants, one physician), 21 (36\%) in interventional radiology or radiotherapy (16 technicians, one hospital attendant, four physicians) of the hospital of the USL-12, Pisa. The mean (SD, range) age at the time of the start of the occupational exposure was $24.8(4.9,18-40)$ years. The mean (SD, range) duration of the occupational exposure was $22(6 \cdot 0,10-39)$ years.

CONTROL GROUP 1

A control group was made up of 130 men 
with a duration of employment of more than 10 years at a shipyard factory in an iodine deficient area (Lunigiana), ${ }^{910}$ without known occupational exposure to radiation.

For each subject exposed to $x$ radiation two unexposed workers were randomly selected, matched for age ( \pm 2 years). Fifty exposed subjects (mean ( $\mathrm{SD}$, range) age $46 \cdot 7(5 \cdot 5$, 33-56)) years, and 100 unexposed subjects (mean (SD, range) age $46.2(5.4,33-57)$ ) years, could be coupled, but nine exposed and 30 unexposed workers were excluded because they were not matchable for age.

The background exposures are $0.8 \mathrm{mSv}$ a year both in Lunigiana and in Pisa.

\section{CONTROL GROUP 2}

A second control group was randomly obtained from 138 men-technicians and clerks-who came to our attention from January to May 1994 for periodic examinations prescribed by the local occupational medicine service. They fitted the following criteria: (a) duration of employment more than 10 years; (b) no known occupational exposure to radiation; (c) no occupational exposure to other substances or agents known to be toxic to the thyroid.

One hundred unexposed workers (mean (SD, range) age $47 \cdot 6(6 \cdot 3,31-59)$ ) years were randomly selected, and were matched for age ( \pm 2 years) with the same 50 subjects exposed to $x$ radiation.

All volunteers for both groups gave their informed consent to take part.

QUESTIONNAIRE AND PHYSICAL EXAMINATION All volunteers completed a questionnaire on family history of thyroid diseases, their history of residence in iodine deficient areas, their health, the use of frequent radiodiagnostic procedures (no more than two chest radiographs a year) or radiotherapeutic procedures in the past, the type of work and of radiation exposure, the use of radioprotective devices. All volunteers were physically examined and thyroid ultrasonography was performed.

\section{ULTRASONOGRAPHY, SCINTIGRAPHY OF THE} NECK, AND FINE NEEDLE ASPIRATION

Neck ultrasonography was always performed by the same two operators. They used a device (Toshiba, Tosbee) with a sectorial probe $7.5 \mathrm{MHz}$ transducer and an interposing water bag. Ultrasonographical examination was blindly conducted for subjects exposed to $x$ ray films and control groups 1 and 2 . The criteria to define the occurrence of thyroid nodular lesions were the following: (a) presence of a hypooechoic, isoechoic or hyperechoic nodular pattern; (b) presence of a perinodular hypoechogenic or hyperechogenic halo; (c) presence of an unechoic lesion with posterior wall reinforced echo as in cystic lesions. Only nodular lesions with a maximum diameter of $>5 \mathrm{~mm}$, and with agreement of both operators were considered.

In patients with thyroid nodules with a diameter of $>1 \mathrm{~cm}$, thyroid scintigraphy was performed with a dual $15 \mathrm{~cm}$ sodium iodide rectilinear scanner (Ital Electronic SPA, Rome, Italy), 48 hours after the test dose of 30-50 $\mu \mathrm{Ci},{ }^{131} \mathrm{I}$.

In patients with thyroid nodules with a diameter of $>1 \mathrm{~cm}$, ultrasonographically guided fine needle aspiration was performed by the same operator with a "free hand" method. Before biopsy the transducer was thoroughly cleaned with alcohol and sterile gel was used as the coupling agent. The calibre of the needles used ranged from 21 to 22 gauge. As one hand takes the syringe, the other hand is free to hold the ultrasound transducer, and the needle position can be continuously seen throughout the insertion and during the actual biopsy. The material is subsequently fixed and stained with a modified Papanicolau technique.

\section{LABORATORY EVALUATION}

Laboratory determination of thyroid function was performed in all subjects of the occupationally exposed group and in subjects of the control groups who had thyroid nodules. Serum thyroxine (T4) and triiodothyronine (T3) were measured directly by radioimmunoassay (RIA) (ARIA HT; Becton Dickinson). Serum thyroid stimulating hormone (TSH) was evaluated by RIA (TSH MYRIA, Techno Genetics, Milan).

\section{STATISTICAL ANALYSIS}

Results were expressed as mean (SD). Crude relative risk and Mantel-Haenszel weighted relative risk were used as measures of association. Student's $t$ test, analysis of variance (ANOVA), $\chi^{2}$, and Mantel-Haenszel $\chi^{2}$, were used as statistical tests. Probability of $\leqslant 0.05$ was considered to be significant. The statistical analysis was performed by the Epi Info (Vs 5.01a) software program. ${ }^{11}$

\section{Results}

QUESTIONNAIRE

Among the occupationally exposed subjects, none had previously received radiotherapy treatment, and none had ever been submitted to frequent (not more than two chest radiographs, or equivalent procedures a year) radiodiagnostic procedures. Four subjects (8\%) had a family history of thyroid disease, and only six of $50(12 \%)$ had a history of residence in iodine deficient areas for 10 years or more.

Among the control subjects of group 1, none had been treated with radiotherapy or had been submitted to frequent radiodiagnostic procedures. Twenty six (26\%) subjects had a family history of thyroid disease. Everybody had a history of residence in iodine deficient areas for 10 years or more.

Of the control subjects of group 2, none had been treated with radiotherapy or had been submitted to frequent radiodiagnostic procedures. Ten $(10 \%)$ subjects had a family history of thyroid disease. None had a history of residence in iodine deficient areas for 10 years or more during the study period or in the past. 
THYROID NODULES

Among the occupationally exposed subjects, thyroid nodules were detected in $19(38 \%)$ subjects (mean ( $\mathrm{SD}$, range) age $46.0(6 \cdot 2$, 33-56)) years. Among the subjects with thyroid nodules, eight (42\%) worked in orthopaedics (two technicians, three hospital attendants, three physicians), two (10.5\%) worked in haemodynamics (two technicians), nine $(47.4 \%)$ in interventional radiology or radiotherapy (seven technicians, two physicians). In 12 cases $(63.2 \%)$ we found single thyroid nodules and in seven $(36.8 \%)$ multinodular goitre. In 10 cases $(52 \cdot 6 \%)$ we found at least one nodule with a diameter of $>10 \mathrm{~mm}$ and in nine $(47.4 \%)$ nodules with a diameter between 5 and $10 \mathrm{~mm}$. Fine needle aspiration was negative for thyroid malignancy. Free T3 and T4 were in the normal range in all subjects with thyroid nodules. Thyroid scintigraphy showed a hyperfunctioning nodule in one case $(5.3 \%)$; in this subject $\mathrm{TSH}$ was suppressed $(\mathrm{TSH}<0.07$ $\mu \mathrm{U} / \mathrm{ml}$ ), which suggested a diagnosis of pretoxic adenoma. All the other patients had normal concentrations of TSH.

Among the control subjects of group 1, thyroid nodules were detected in $19(19 \%)$ subjects (mean (SD, range) age $48.3(5 \cdot 2$, $38-56)$ years). In 10 cases $(52 \cdot 6 \%)$ we found single thyroid nodules and in nine $(47.4 \%)$ a multinodular goitre. In 10 cases $(52.6 \%)$ we found at least one nodule with a diameter of $>10 \mathrm{~mm}$ and in nine $(47 \cdot 4 \%)$ nodules with diameters between 10 and $5 \mathrm{~mm}$. Fine needle aspiration was negative for thyroid malignancy. Free T3, T4 and TSH were in the normal range in all subjects with thyroid nodules. Thyroid scintigraphy showed no hyperfunctioning nodules.
Table 1 Distribution of subjects with and without thyroid nodules by age in control group 1 (from an iodine deficient area) and in the group exposed to radiation

\begin{tabular}{|c|c|c|c|c|c|}
\hline \multirow[b]{2}{*}{ Age } & \multicolumn{2}{|l|}{ Exposed } & \multicolumn{2}{|c|}{ Control group 1} & \multirow{2}{*}{$\frac{\text { Statistical analysis }}{R R(95 \% C I)}$} \\
\hline & $\begin{array}{l}\text { With } \\
\text { nodules }\end{array}$ & $\begin{array}{l}\text { Without } \\
\text { nodules }\end{array}$ & $\begin{array}{l}\text { With } \\
\text { nodules }\end{array}$ & $\begin{array}{l}\text { Without } \\
\text { nodules }\end{array}$ & \\
\hline $\begin{array}{l}30-39 \\
40-49 \\
50-59\end{array}$ & $\begin{array}{r}3 \\
10 \\
6\end{array}$ & $\begin{array}{r}2 \\
19 \\
10\end{array}$ & $\begin{array}{r}1 \\
10 \\
8\end{array}$ & $\begin{array}{r}9 \\
55 \\
17\end{array}$ & $\begin{array}{l}6 \cdot 00^{\star}(0 \cdot 82-44 \cdot 0) \\
2 \cdot 24^{\star}(1 \cdot 05-4 \cdot 79) \\
1 \cdot 17^{\star}(0 \cdot 50-2 \cdot 75)\end{array}$ \\
\hline Total & 19 & 31 & 19 & 81 & $\begin{array}{l}2.00^{\star}(1 \cdot 17-3.42) \\
1.92 \dagger(1.13-3.27)\end{array}$ \\
\hline
\end{tabular}

$\star=$ Crude relative risk (Taylor series $\mathrm{CIs}$ ); $\dagger=$ Mantel-Haenszel weighted relative risk (Greenland-Robins CIs).

Table 2 Distribution of subjects with and without thyroid nodules by age in control group 2 (from Pisa) and in the group exposed to radiation

\begin{tabular}{|c|c|c|c|c|c|}
\hline \multirow[b]{2}{*}{ Age } & \multicolumn{2}{|l|}{ Exposed } & \multicolumn{2}{|c|}{ Control group 2} & \multirow{2}{*}{$\frac{\text { Statistical analysis }}{R R(95 \% C I)}$} \\
\hline & $\begin{array}{l}\text { With } \\
\text { nodules }\end{array}$ & $\begin{array}{l}\text { Without } \\
\text { nodules }\end{array}$ & $\begin{array}{l}\text { With } \\
\text { nodules }\end{array}$ & $\begin{array}{l}\text { Without } \\
\text { nodules }\end{array}$ & \\
\hline $\begin{array}{l}30-39 \\
40-49 \\
50-59\end{array}$ & $\begin{array}{r}3 \\
10 \\
6\end{array}$ & $\begin{array}{r}2 \\
19 \\
10\end{array}$ & $\begin{array}{l}1 \\
6 \\
6\end{array}$ & $\begin{array}{l}12 \\
56 \\
19\end{array}$ & $\begin{array}{l}7 \cdot 80^{\star}(1 \cdot 04-58 \cdot 48) \\
3 \cdot 56^{\star}(1 \cdot 43-8 \cdot 86) \\
1 \cdot 56^{\star}(0 \cdot 61-4 \cdot 01)\end{array}$ \\
\hline Total & 19 & 31 & 13 & 87 & $\begin{array}{l}2.92^{\star}(1.57-5.43) \\
2.79 \dagger(1.53-5.10)\end{array}$ \\
\hline
\end{tabular}

$\star$ = Crude relative risk (Taylor series $\mathrm{CIs}$ ); $+=$ Mantel-Haenszel weighted relative risk (Greenland-Robins CIs).
Among the control subjects of group 2, thyroid nodules were detected in $13(13 \%)$ subjects (mean ( $\mathrm{SD}$, range) age $46.7(6.8$, 40-58) years). In seven cases $(53 \cdot 8 \%$ ) we found single thyroid nodules and in six $(46 \cdot 2 \%)$ a multinodular goitre. In five cases (38.5\%) we found at least one nodule with a diameter of $>10 \mathrm{~mm}$ and in eight cases $(61.5 \%)$ nodules with diameters between 10 and $5 \mathrm{~mm}$. Fine needle aspiration was negative for thyroid malignancy. Free T3, T4 and TSH were in the normal range in all subjects with thyroid nodules. Thyroid scintigraphy showed no hyperfunctioning nodules.

\section{STATISTICAL ANALYSIS}

After the matching procedure, the ages of the occupationally exposed group and the control groups were not significantly different (ANOVA). The ages of subjects with nodules in the exposed and the non-exposed groups were not significantly different. The control group 1 had a significantly higher prevalence of family history of thyroid diseases and history of residence in iodine deficient areas than the control group 2 and the group exposed to $x$ radiation. The comparison of prevalence of thyroid nodules in each age class between the two control groups showed a higher prevalence (not significant) in group 1 (from the Lunigiana iodine deficient areas). The prevalence of thyroid nodules was significantly higher in exposed subjects than in both control group $1\left(\chi^{2} 5 \cdot 39 ; P=0.02\right)$ and control group $2\left(\chi^{2} 10.97 ; P=0.0004\right)$. The prevalence of thyroid nodules in the age groups 30-39, 40-49, and 50-59 was higher in subjects exposed to radiation (tables 1 and 2).

The relative risk for thyroid nodules was very high but not significant in the age group 30-39, it was high and significant in the age group 40-49, and close to 1 in the age group 50-59 in subjects exposed to radiation compared with control group 1 (table 1). Furthermore, for three levels of occupational exposure (non-exposed; duration of occupational exposure from 10 to 19 years, or more than 20 years), Mantel-Haenszel relative risk weighted for age proved to be significant for subjects with $\geqslant 20$ years of work $(2.00 ; 95 \%$ confidence interval (95\% CI) $1 \cdot 16-3 \cdot 43)$, and it was high but not significant for subjects with exposure of between 10 and 19 years (1.80; 95\% CI 0.66-4.94) compared with control group 1. The relative risk for thyroid nodules, from the comparison between exposed subjects and control group 2, was high and significant in the 30-39 and 40-49 year age groups, and high but not significant in subjects of 50-59. Both the total crude relative risk and the Mantel-Haenszel weighted relative risk were significant (table 2). Furthermore, for the three levels of occupational exposure (non-exposed; duration of occupational exposure of 10-19 years; or $\geqslant 20$ years) Mantel-Haenszel relative risk weighted for age was significant for subjects with $\geqslant 20$ years of work $(2 \cdot 86 ; 95 \%$ CI $1 \cdot 56-5 \cdot 25)$ and was high but not significant 
for subjects with exposure of between 10 and 19 years $(2 \cdot 71 ; 95 \%$ CI $0 \cdot 92-7 \cdot 09)$ compared with control group 2.

\section{Discussion}

Only a few studies have evaluated the effects of long term, low dose exposure on the thyroid..$^{5-8}$ Most of these found a high prevalence of thyroid cancer and nodules in subjects occupationally exposed to radiation.

Kendall et al conducted a retrospective cohort mortality study in radiation workers from major sites of the nuclear industry $(62 \%$ of the workers had a lifetime dose $<10 \mathrm{mSv}$, and only $9 \%$ had a lifetime dose $>100 \mathrm{mSv}$ ), and showed a high prevalence of thyroid cancer. ${ }^{8}$

In a retrospective study of hospital records of 27011 medical diagnostic $x$ ray film workers in China, Wang et al found a high prevalence of thyroid cancer. ${ }^{612}$

Boice $e t a l$, in a retrospective survey on the American Registry of Radiologic Technologists found a high prevalence of thyroid cancer and nodules in sanitary personnel exposed to radiation ${ }^{5}$; the prevalence of thyroid nodules was lower than that found in our study, but their data only referred to clinically evident conditions, shown by a questionnaire, whereas our data were obtained by ultrasonographic evaluation of the neck. Furthermore, the studied population was not homogeneous for the extent and duration of exposure and dosimetric data were available for only about $20 \%$ of the studied population, so it is difficult to make a comparison with our data.

Andersson et al in a retrospective survey from the Danish Cancer Registry, have not found an increased risk for thyroid cancer in 4151 subjects from radiotherapy personnel in Denmark compared with the general population. ${ }^{7}$ For others ${ }^{5} 6812$ and in our study, however, the cumulative dose of radiation exposure was low (mean 18.4 mSv; $61 \%$ $<5 \mathrm{mSv}$ ) and the duration of exposure was brief $(61 \%<3$ years, $23 \% 3-5$ years, and only $15 \%>5$ years $)$.

Fraser et al studied workers both with and without exposure to radiation, and found a higher prevalence of thyroid cancer in the non-exposed group. ${ }^{13}$

In our study the prevalence of nodular disease of the thyroid has been studied cross sectionally by ultrasonography in men exposed to radiation for $>10$ years through medical occupational exposure compared with age matched non-exposed controls.

It is well known that the main risk factors for thyroid nodules are female sex, old age, ${ }^{14}$ and iodine deficiency. ${ }^{15}$ The severity of iodine deficiency may be very different from one area to another in the same region-for example, Tuscany. ${ }^{91016}$ Moreover, in the same area iodine deficiency has been changing over the past decades, so the actual prevalence of thyroid goitre and urinary iodine excretion often does not reflect the severity of iodine deficiency in the past. ${ }^{17}$ For these reasons, although it is relatively simple to match subjects exposed and not exposed to $x$ radiation for age and sex, it is very difficult to match patients for the personal history of residence in iodine deficient areas. As in many other towns of Europe, many people came in the past from the surrounding rural areas to work and live in Pisa; so we had to expect that some exposed workers could have been resident in the past in iodine deficient areas of Tuscany. In fact six (12\%) exposed subjects had lived in iodine deficient areas of Tuscany for more than 10 years and others for shorter periods. For these reasons, at first we selected a control group of workers (group 1) from a slightly iodine deficient area of Tuscany (Lunigiana) where the mean urinary iodine excretion is about $49.8 \mu \mathrm{g} /$ day, $^{9}{ }^{10}$ and the prevalence of clinically evident goitre in children between eight and 14 years of age is $56 \% . .^{9}{ }^{10}$ Later we decided to match the exposed subjects with a control group from the same area (Pisa, group 2 ), where the mean urinary iodine excretion is about $88 \mu \mathrm{g} /$ day $^{9}$ and the prevalence of clinically evident goitre in children between eight and 14 years of age is $5 \cdot 6 \% .^{16}$

The number of subjects with a familial history of thyroid disease is high in the nonexposed group 1. This reflects the presence of endemic goitre in the Lunigiana area due to iodine deficiency. ${ }^{9} 10$ Endemic goitre is well known to be an important risk factor for thyroid nodules, ${ }^{15}$ and it is not present in the Pisa area where the exposed group works. The comparison of the prevalence of thyroid nodules between the two control groups shows a higher prevalence in group 1 that is due to the iodine deficiency in the Lunigiana area. The absence of a significant difference for age between the exposed group and control groups (due to matching) and the higher prevalence of familial history of thyroid disease and of history of residence in iodine deficient areas in the non-exposed subjects should suggest a higher prevalence of thyroid nodules in that group. ${ }^{17}$ On the contrary, the prevalence of thyroid nodules was significantly higher in exposed subjects. The prevalences of thyroid nodules in the 30-39, 40-49 and 50-59 year old age groups are higher for each age class in men exposed to radiation than in the non-exposed groups, especially in young men. This suggests that thyroid nodules appear at a younger age in the subjects exposed to radiation. The risk is higher in the subjects exposed to $x$ radiation when compared with the control group from Pisa than with the control group from Lunigiana, because of the absence of iodine deficiency in Pisa. The risk seems to be higher in the younger age groups even if, owing to the small numbers of subjects in each age group, it is not possible to say that the differences among the age groups are significant.

In conclusion, our study suggests that long term, low dose, occupational exposure to radiation may be a risk factor for thyroid nodules. Thyroid nodules may be regarded as clinical markers of radiation exposure and 
from experimental studies suggestive of a progression from thyroid nodules to thyroid cancer in animals exposed to radiation. ${ }^{18}$ It is necessary, therefore, to perform accurate medical surveillance to prevent this problem in the workers occupationally exposed to radiation.

1 De Groot LJ, Reilly M, Pinnameneni K, et al. Retrospective and prospective study of radiationinduced thyroid disease. Am f Med 1983;74:852--9.

2 Shore RE, Albert RE, Pasternack BS. Follow-up study of patients treated by $\mathrm{x}$-rays epilation for tinea capitis; resurvey for post-treatment illness and mortality experisurvey for post-treatment ilness and mor

3 United Nations Scientific Committee. Effects of atomic radiation. Ionizing radiation, levels and effects. Vol II. Report of the official records of the general assembly, session 27. New York: United Nations, 1972. (Suppl No 25 (A/8725)

4 Kingman S. Thyroid cancer rises after Chernobyl. BMF 1992;305:601-2

5 Boice JD Jr, Mandel JS, Doody MM, Yoder RC, McGowan RA. Health survey of radiologic technologists. Cancer 1992;69:586-98.

6 Wang JX, Inskip PD, Boice JD Jr, Li RX, Zhang JY, Fraumeni JF. Cancer incidence among medical diagnosFraumeni JF. Cancer incidence among medical diagnos-
tic $x$ ray workers in China, 1950 to 1985 . Cancer 1990; tic $x$ ray work
$45: 889-95$.

7 Andersson M, Engholm G, Ennow K, et al. Cancer risk among staff at two radiotherapy departments in Denmark. Br $\mathcal{F}$ Radiol 1991;64:455-60.
8 Kendall GM, Muirhead CR, MacGibbon BH, et al. Mortality and occupational exposure to radiation: first analysis of the National Registry for Radiation Workers. BMF 1992;304:220-5.

9 Baschieri L, Pruneti CA, Antonelli A, et al. Neuropsychological development of school-children in the moderately iodine-deficient area of Lunigiana (Tuscany). Iodine Deficiency Diseases Newsletter 1988;4: 10-1.

10 Donati L, Baracchini-Muratorio G, Baschieri L. Neuropsychic development of "normal school-children" from iodine deficient areas. $\mathcal{F}$ Endocrinol Invest 1991;14 $697-9$

11 Dean J, Dean A, Burton A, Dicker R. Epi Info software program (Vs. 5.01a). EPO, Atlanta: Center for Disease Control, 1991

12 Wang JX, Bojce JD Jr, Li BX, Zhang JY, Fraumeni JF Jr. Cancer among medical diagnostic $x$ ray workers in China. 7 Natl Cancer Institute $1988 ; 80: 344-50$.

13 Fraser P, Carpenter L, Maconochie N, et al. Cancer mortality and morbidity in employees of the United Kingdom Atomic Energy Authority, 1946-86. Br f Cancer 1993;67:615-24.

14 Mazzaferri EL. Management of a solitary thyroid nodule. $N$ Engl f Med 1993;328:553-9.

15 Gaitan E, Nelson NC, Poole GV. Endemic goitre and endemic thyroid disorders. World f Surg 1991;15 205-15

16 Donati L, Antonelli A, Bertoni F, et al. Clinical picture of endemic cretinism in Central Apennines (Montefeltro) Thyroid 1992;2:283-90.

17 Brander A, Viikinkoski P, Nickels J, Kivisaari L. Thyroid gland: US screening in a random adult population. gland: US screening in

18 Williams ED. Biological effects of radiation on the thyroid In: Ingbar SH, Braverman LE, eds. The thyroid, 6th ed Philadelphia: JB Lippincot, 1991:421-36.

\section{Vancouver style}

All manuscripts submitted to Occup Environ Med should conform to the uniform requirements for manuscripts submitted to biomedical journals (known as the Vancouver style.)

Occup Environ Med, together with many other international biomedical journals, has agreed to accept articles prepared in accordance with the Vancouver style. The style (described in full in the $B M \mathcal{F}, 24$ February $1979, \mathrm{p}$ 532) is intended to standardise requirements for authors.

References should be numbered consecutively in the order in which they are first mentioned in the text by Arabic numerals above the line on each occasion the reference is cited (Manson ${ }^{1}$ confirmed other reports $^{25}$....). In future references to papers submitted to Occup Environ Med should include: the names of all authors if there are seven or less or, if there are more, the first six followed by et al; the title of journal articles or book chapters; the titles of journals abbreviated according to the style of Index Medicus; and the first and final page numbers of the article or chapter. Titles not in Index Medicus should be given in full.

Examples of common forms of references are:

1 International Steering Committee of Medical Editors, Uniform requirements for manuscripts submitted to Uniform requirements for manuscripts submit
biomedical journals. $B r M e d ~$
$71979 ; 1: 532-5$

2 Soter NA, Wasserman SI, Austen KF. Cold urticaria: release into the circulation of histamine and eosinorelease into the circulation of histamine and eosino-
phil chemotactic factor of anaphylaxis during cold phil chemotactic factor of anaphylaxis duri
challenge. N Engl f Med 1976;294:687-90.

3 Weinstein L Swartz MN. Pathogenic properties of Weinstein L, Swartz MN. Pathogenic properties of
invading micro-organisms. In: Sodeman WA Jr, Sodeman WA, eds. Pathologic physiology, mechanism of disease. Philadelphia: W B Saunders, 1974:457-72. 